\title{
Influence of Anisotropy Properties of as-Rolled C- Mn Plate on Welding Induced Distortion
}

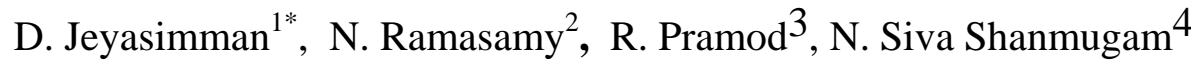 \\ ${ }^{1 \& 2}$ Department of Mechanical Engineering, Periyar Maniammai Institute of Science \\ and Technology, Vallam, Thanjavur- 613 404, India.
}
${ }^{3 \& 4}$ Department of Mechanical Engineering, National Institute of Technology, Tiruchirappalli-620 015, India.

E-Mail: jeyasimman76@gmail.com,nrambhel@gmail.com,prdshankar@gmail.com \&nsiva@nitt.edu

\begin{abstract}
Welding induced distortion remain persistent problems leading to the inferior on Product Quality. The study is to investigate on welding induced angular distortion due to effect of anisotropy properties of the As-rolled C-Mn plate. The outcome could enhance the minimum distortion while cutting the raw material on rolling direction for fabrication process. The Anisotropy properties of the base metal were analyzed with along and transverse to rolling direction through microstructure examination, hardness measurement and mechanical properties. Microstructure contains coarse grains of pearlite and ferrite in transverse to rolling, whereas fine grains along the rolling. Hardness was 80 and 84 HRB along and transverse to rolling respectively. A weld bead was laid on the plate's substrate with along and transverse to the rolling and angular deflections were measured with a dial gauge indicator. Finite element analysis (FEA) was carried out to evaluate the angular deflection on both the rolling. From the experimental results, the anisotropy properties of the as-rolled plate had influenced on angular deflection and indicating with good agreement with FEA.
\end{abstract}

Keywords: As rolled plate; Anisotropy properties; Bead on plate; Deflection; Finite element.

\section{INTRODUCTION}

Welding is a process of joining the similar materials or dissimilar materials to achieve complete coalescence. This process is enabled by the application of heat and pressure by fusion of joining with the same material or by the addition of filler materials to develop monolithic structure. In spite of its advantages, deficiency in welding induced distortion and including residual stresses. Any unwanted shape change in fabricated structure because of welding is called welding induced distortion. Welding distortion is one of the acute problems in manufacturing industries. During welding, the weld location may undergo localized heating induces non-uniform expansion, which is constrained by bulk surrounding cold base metal. Material expansion is proportional to the temperature change and thermal expansion coefficient. The difference in temperature during cooling, leads to non-uniform thermal stain. If the thermal stresses induced into the material due to localized heating and subsequent cooling exceeds the yield strength of base material, manifested localized plastic deformation. The residual plastic strains that remain after the thermal cycle that leads to shape change. This shape change is termed as welding distortion [1] that occurs in multiple directions. Several factors are responsible for contributing to welding induced distortion. 
Hot rolling is a plastic deformation process, where the material is deformed above the recrystallization temperature [2]. Plate rolling process is done inbetween compressive rollers that rotate in opposite directions. The intensity of deformation depends on the rolling pressure. Microstructures developed during rolling remain a crucial factor for the physical properties of rolled products [3]. The crystal grains can elongate to a certain crystallographic direction and aligned with the rolling direction. The physical properties are varying with crystal grain orientation and depend on rolling direction causes anisotropic behaviour [4]. The banding structure of ferrite and pearlite microstructure is manifested during plate rolling. The plastic deformation produced in the base metal during welding is the function of the metallurgical condition of the base metal as well as weld metal. In the past decades, many methods have been developed to predict the welding distortion and many procedures have been established [5-7]. However, there is limited literature describing the influence of anisotropy properties on welding induced distortion. Accurate prediction of welding induced distortion is critical to improving the Quality of the welded structure. The purpose of this investigation is to find out the welding induced deflection with respect to plate rolling direction. In this study, anisotropy properties of the As- rolled plate with along rolling and transverse to rolling directions were evaluated by Microstructure examination and Mechanical properties. A weld bead was laid along and transverse to the rolling direction of the low Carbon Manganese (C-Mn) steel plate substrate. The welding heat input was simulated by the FEA. The welding induced deflections were compared with experiments and FEA. The test results showed that the output was good agreement with FEA and experiments.

\section{EXPERIMENTAL PROCEDURE}

\subsection{Mechanical test}

Low Carbon Manganese steel plate with specification IS 2062 E250 A, was identified for experiments. Two test plate specimens were marked in the same plate and prepared, one for along rolling direction and another for transverse to rolling direction. Flat tensile tests (ASTM A370) were conducted for the base metal representing $\mathrm{A}$ for the rolling direction and $\mathrm{B}$ for transverse to rolling direction in calibrated Universal testing machine UTE-60. The test values are tabulated in Table 1.

Table.1. Mechanical properties.

\begin{tabular}{|l|c|c|c|}
\hline \multicolumn{1}{|c|}{ Description } & $\begin{array}{c}\text { Tensile } \\
\text { stress, } \\
\text { MPa }\end{array}$ & $\begin{array}{c}\text { Yield } \\
\text { stress, } \\
\text { MPa }\end{array}$ & Elongation, \% \\
\hline Along the rolling direction, A & 496 & 322 & 22.14 \\
\hline $\begin{array}{l}\text { Transverse to the rolling } \\
\text { direction, B }\end{array}$ & 504 & 319 & 20.73 \\
\hline
\end{tabular}

\subsection{Bead on plate}

As rolled plate size $100 \mathrm{~mm}$ width, $150 \mathrm{~mm}$ length and $8 \mathrm{~mm}$ thick, were prepared from same plate, and centerline was marked in each plate to deposit weld along the marked line. Shielded Metal Arc Welding (SMAW) 
process was employed, and baked flux coated stick electrode E 7018 (American Welding Society D 1.1) was used with a $4 \mathrm{~mm}$ diameter. Singlepass weld bead was laid on the plate along the plate rolling direction and transverse to the rolling direction with a down hand position. The welding parameters followed for both experiments are presented in Table 2. The schematic representation for Welding Direction (WD), Plate Rolling Direction (PRD), and angular deflection of the bead on plate are shown in Fig.1.(a) \& (b).

\subsection{Deflection measurement}

One end of the welded specimen bent portion was placed on the block as flat, and another end was kept as free to measure the deflection. The schematic diagram for the measurement method is represented in Fig.2. The dial gauge indicator moved incrementally from free end to center of the weld, and corresponding dial gauge readings were recorded. The angular deflection was equated by dividing $h / 2$. The estimated deflection values were recorded.
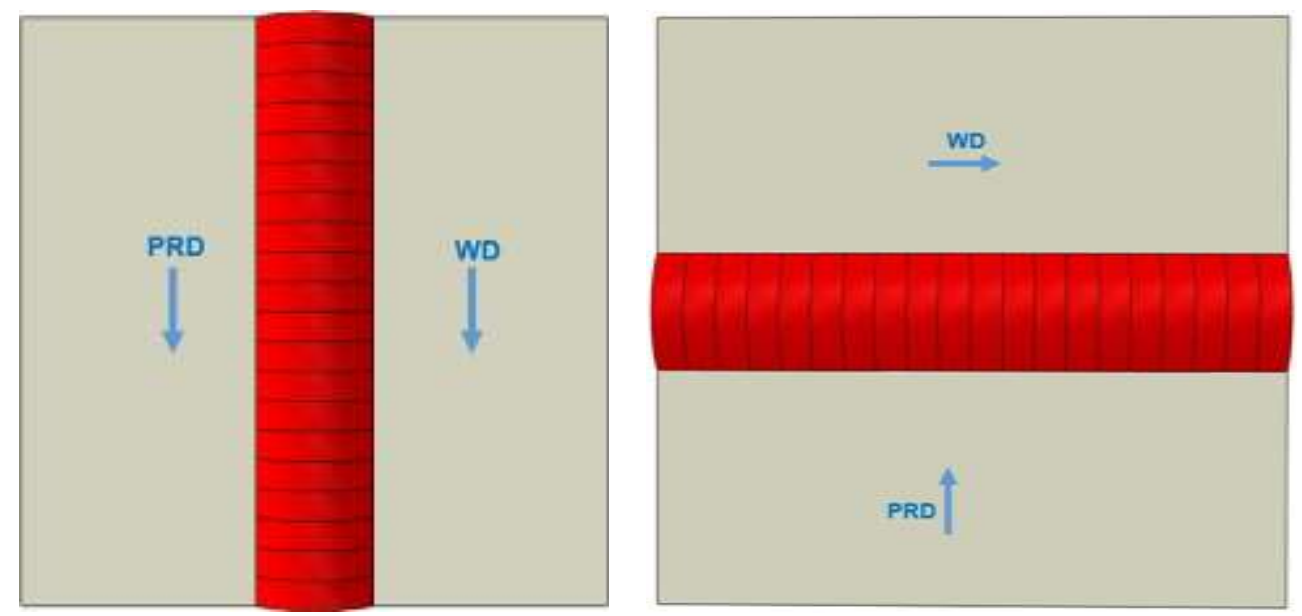

Figure 1. Weld (a) along rolling direction; (b) Weld transverse to rolling direction

\subsection{Hardness test}

The test specimen welded along the rolling and transverse to rolling were cut in transverse to the weld run direction. The cut sections were machined and etched with natal solution to identify the weld metal and HAZ. Hardness test was conducted as per IS 1501-2002 on the sample by applying load $100 \mathrm{kgf}$ for 15 seconds duration in the hardness testing machine. Rockwell hardness (B scale) values (HRB) were measured at various locations such as base metal, HAZ, and weld metal, and average hardness values were estimated and recorded.

Table 2. Welding parameters

\begin{tabular}{|c|c|c|c|}
\hline Process & Current (A) & Volt $(\mathbf{V})$ & Welding speed S $\left(\mathbf{m m}-\mathbf{s}^{-1}\right)$ \\
\hline SMAW & 180 & 25 & 2.12 \\
\hline
\end{tabular}

\subsection{Microstructure examination}

The welded specimen was sectioned across the welding direction and machined for microstructure examinations. Cross-section of the test specimen was polished with different grades of emery paper and etched 
with a 2 percent (volume) nital solution. The prepared specimens were examined by an optical microscope at HAZ and base metal.

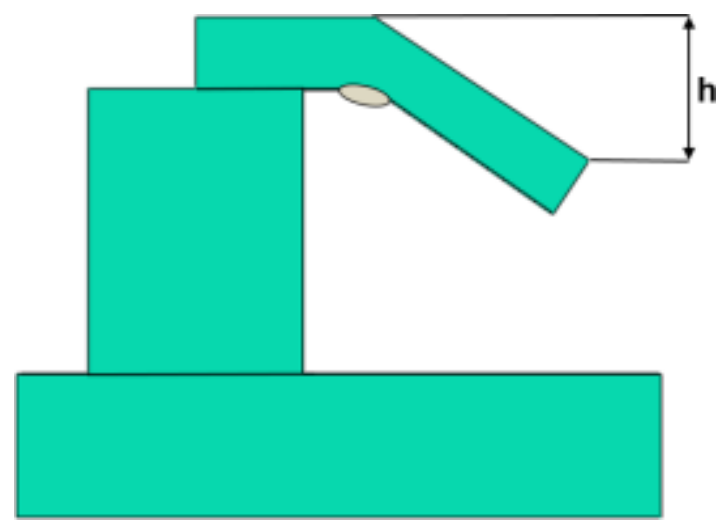

Figure 2. Angular deflection measurement

\subsection{Finite Element Modelling}

3D finite element model was developed and calculated using finite element ABAQUS 2018 software code to simulate the complete SMAW process. The plate geometry and coordinate system marked with the dimensions in meter is shown in Fig.3. A structured meshing technique with seed sizes 5 millimetres was adopted, and 1200 elements with hexagonal shape were generated. 3D, 8 nodes (C3D8T) thermally coupled brick; trilinear displacement and temperature were selected for the thermal analysis after performing mesh convergence tests. The global coupled thermo-mechanical Gaussian heat source model was used to predicts the transient temperature, strain, and distortion fields for both weld types, and process parameters, i.e., arc power, welding speed, and heat input reliably. Coupled temperature displacement transient analysis, Nonlinear geometric effect was considered.

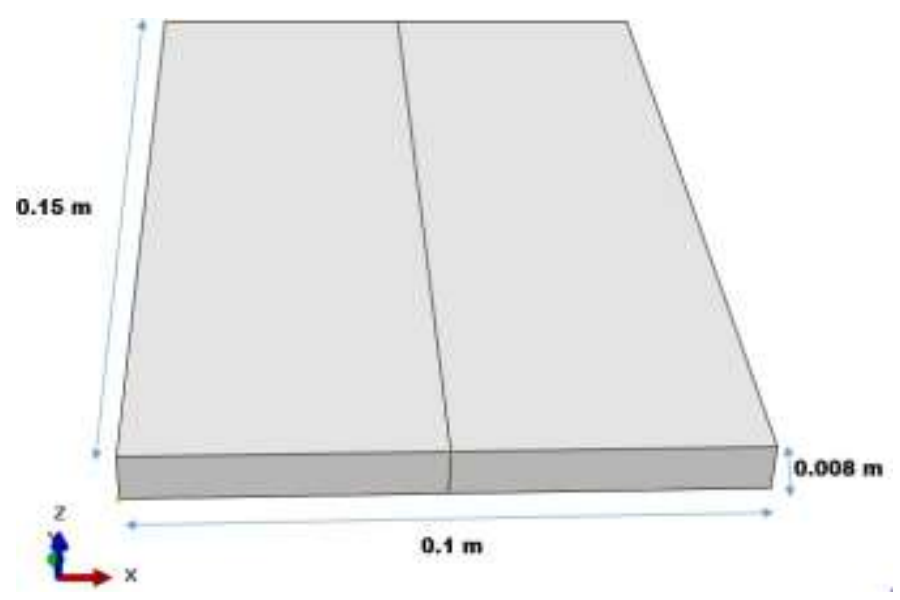

Figure 3. Plate geometry and coordinate system

\section{RESULTS AND DISCUSSION}

\subsection{Analysis of anisotropy properties of base metal}

\subsubsection{Mechanical properties}


Hot rolling process includes control of reheating temperature, reduction rate, finishing rolling temperature and cooling rate. The purpose of these controls is to get an optimum grain size and strength. Finishing rolling temperature is an important parameter among the other parameters. Because of the rolling process, the austenite is deformed, and its dislocation density increases [8]. The forming of new grains and followed by the coarsening of the recrystallized grain structure after rolling. Deformation during the rolling process causes a significant change in microstructure, dislocation density and grain orientation in certain directions. The physical property depends on the rolling direction and intensity of deformation.

The temperature reached to the melting temperature during welding and cooled down after completion of process. At a point of interest, increase in temperature, decreases the yield strength of the base metal and simultaneously thermal expansion of the metal being welded. Low temperature zone of surrounding metal restricts the thermal expansion in turn developed compressive strain in the metal during welding. Compressive strain initially increased with non-linearly due to temperature, variation in yield strength and thermal expansion coefficient of metal. When the temperature was begins to decrease gradually after welding, the reduction in temperature was causing shrinkage of the base metal in fusion zone. The contraction occurred without much resistance at high temperature due to low yield strength of the material. On further cooling, thermal upsetting occurred at the yield strength of the material at lower critical temperature and thereby distortion encountered. Yield strength remains a critical parameter in steel when a steel product fabricated by welding. The welding distortion is mainly depending on yield strength not on tensile strength. Tensile test was conducted for determining the static properties of material on both the rolling direction and represented in Fig. 4.(a) and Fig.4.(b). respectively. From the mechanical test, the tensile value was $496 \mathrm{MPa}$ and $504 \mathrm{MPa}$ for along the rolling direction and transverse to rolling direction respectively. The yield strength was estimated $322 \mathrm{MPa}$ and $319 \mathrm{MPa}$ for rolling and transverse to rolling direction respectively. Yield strength of the material was considered for the analysis and other characters such as deformation rate, strain measurement were neglected. The test values were accounted for both cases and the calibration error of the testing machine was neglected.
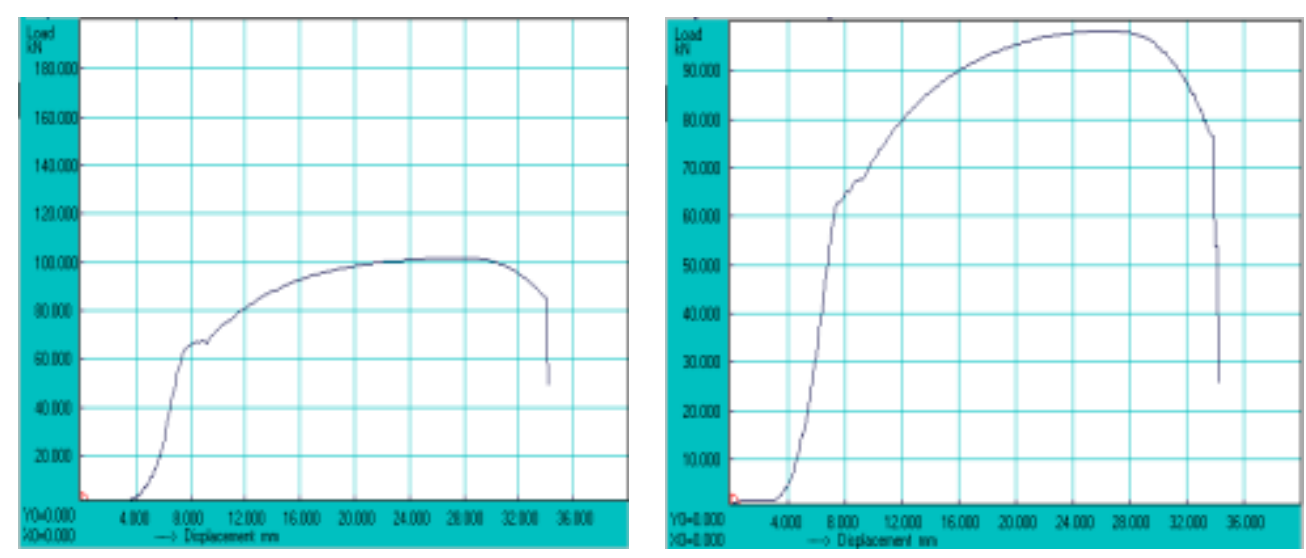

Figure 4 . Tensile test along (a) rolling direction;( b) transverse to rolling direction. 


\subsubsection{Microstructure analysis of base metal}

The hot rolled plate microstructure consists of ferrite bands (white) and alternate bands of pearlite (black). Ferrite-pearlite banding microstructure was responsible for mechanical properties of hot rolled plate. Pearlite appears dark because the ferrite-cementite lamellae of the pearlite are fine to be solved in the light microscope. The base metal microstructure is captured for transverse to the rolling direction and shown in Fig.5.(a). From the Fig.5.(a), the microstructure was relatively coarse grains of ferrite and pearlite. The coarse grains were attributed due to recrystallization and cooling rate. Tensile strength was $504 \mathrm{MPa}$, and yield strength was $319 \mathrm{MPa}$. Higher tensile strength was attributed due to coarse grains of microstructure and low yield strength attributed because of slip at grain boundaries. The microstructure of the base metal along the rolling direction is shown in Fig.5.(b) Fine grains of ferrite and pearlite were observed in the base metal. The fine grains were attributed due to elongation of grains along the rolling and recrystallization after rolling. The yield strength was $322 \mathrm{MPa}$, and the tensile strength was $496 \mathrm{MPa}$. Fig.7 and 8 were compared and found that the coarse grains have higher tensile strength and relatively lower yield strength. Further to analysis, the grain size was evaluated by comparison method of ASTM E112 and compared. ASTM Grain No.7 was observed along the rolling direction and ASTM Grain no. 6.5 was observed transverse to the rolling direction. The variation in microstructure with rolling direction was validated with grain size.
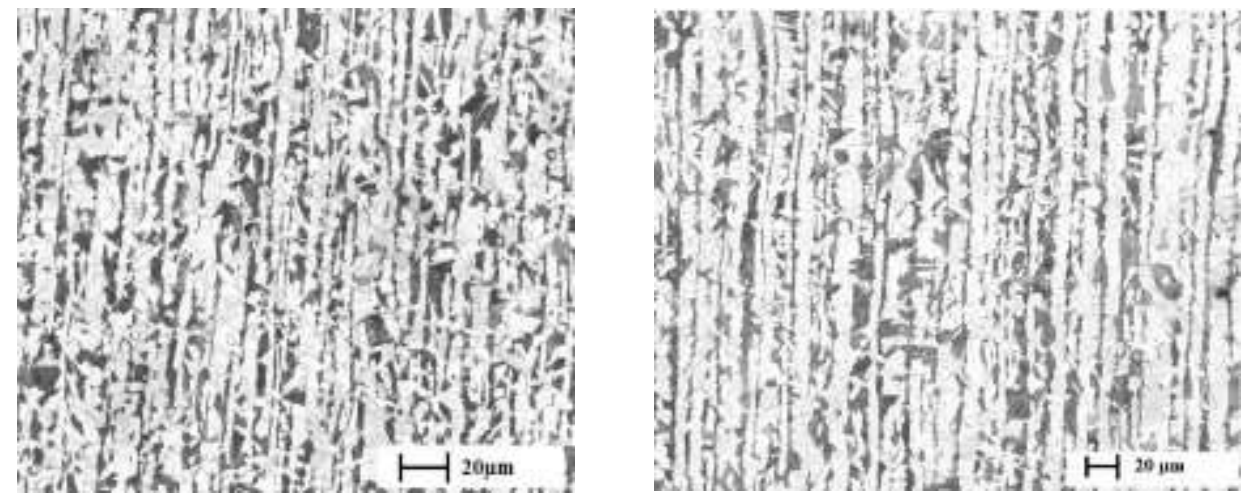

Figure 5. Base metal microstructure along (a) transverse to rolling direction ;( b) rolling direction.

\subsubsection{Microstructure analysis of the welded specimen}

Welded test plate was sectioned transverse to weld run, where the welding was laid along the rolling direction. Depending on phase transformation behaviour in every region of a weld and HAZ, the hardness happens to vary with the integration of microstructure at various regions [11]. The microstructurec a ptured transverse to rolling in HAZ is shown in Fig.9. Microstructure across the weld was analyzed, and the structure revealed that the coarse grains of tempered bainite across the rolling direction. C-Mn steel $<0.3 \% \mathrm{C}$, undergoes minor hardening effect at Heat affected zones (HAZ) and generally were welded with or without preheating. The microstructure was completely different in HAZ than compared to the base metal. The coarse grains of tempered bainite structure at HAZ were due to phase transformation during welding and structural properties while hot rolling of the base metal. The welding induced distortion was $0.73 \mathrm{~mm}$, where the hard microstructure was 
observed in the HAZ [12]. Welded test plate was sectioned transverse to weld run, where the welding was laid transverse to the rolling direction. The microstructure captured along the rolling in HAZ is shown in Fig.6.(a). The microstructure reveals that the fine grains of tempered bainite. Polygonal ferrite and ferrite bands were formed into pearlite grains that form ferrite structure. The structural properties formed along rolling direction had attributed the formation of fine grains of tempered bainite. The welding induced distortion was $0.44 \mathrm{~mm}$ due to the extent of microstructure revealed in the HAZ.

\subsubsection{Hardness analysis on base metal and welded specimen}

Many factors are responsible for the hardness variation across the fusion zones during welding heat input along and transverse of the plate rolling direction. The hardness test is to assess the mechanical properties such as strength, ductility, and resistance to abrasion/wear.

Hardness testing represents a conventional approach to describe the mechanical properties of the material in various zones. The hardness of steel varies depending upon the rolling process treatment. The hardness could be changed and non-uniform based on work hardening (i.e., as rolled). The magnitude of hardness for any given microstructure is a function of the cooling rate.
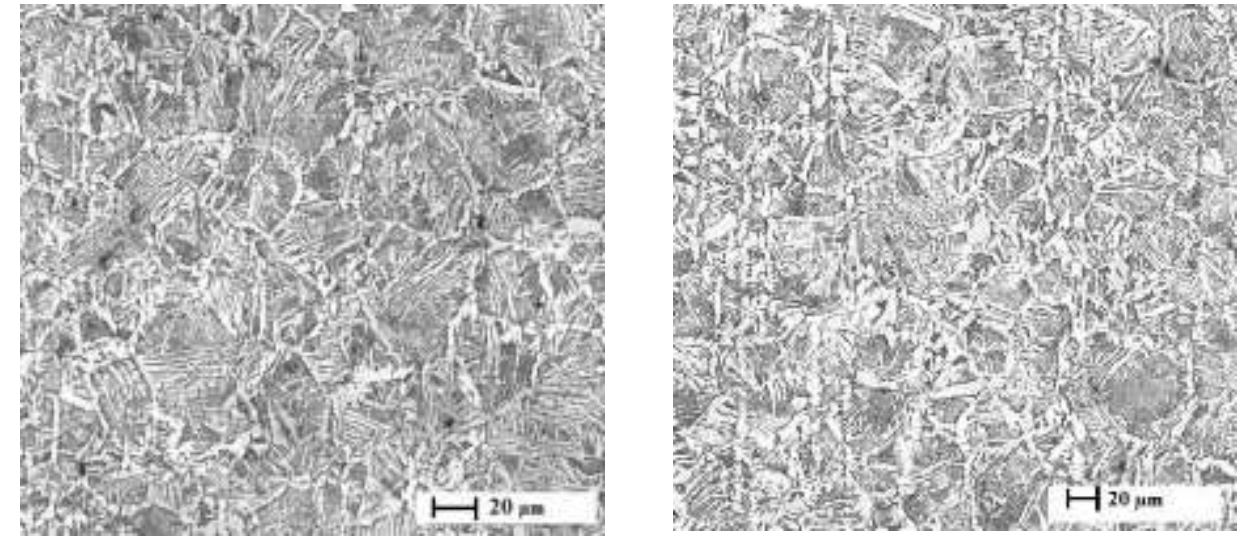

Figure 6. Microstructure at weld HAZ cut section along (a) transverse to rolling direction ;( b) rolling direction.

The microstructure such as ferrite and pearlite present in as rolled carbon steel could be formed into a mixture of bainite and martensite during welding. These formations of various microstructures are according to alloying elements present in base materials. The resultant hardness includes heat input, cooling rate, base metal microstructural conditions and thickness of weld metal. The hardness value of the test specimen at the base metal, HAZ and weld metal across the thickness are graphically represented in Fig.6. (b). From the test results, the hardness was $94 \mathrm{HRB}$ in HAZ, whereas $84 \mathrm{HRB}$ in base metal transverse to the rolling direction. The hardness was $90 \mathrm{HRB}$ in HAZ, whereas $80 \mathrm{HRB}$ in base metal along the rolling direction. The angular deflection was comparatively high when the hardness was high. Where the hardness was low in HAZ and the distortion was also low. Hardness shift was observed from the Fig.7, for the both rolling direction. The magnitude of welding induced angular deflection was validated by the extent of hardness presented in HAZ for carbon manganese steel. 


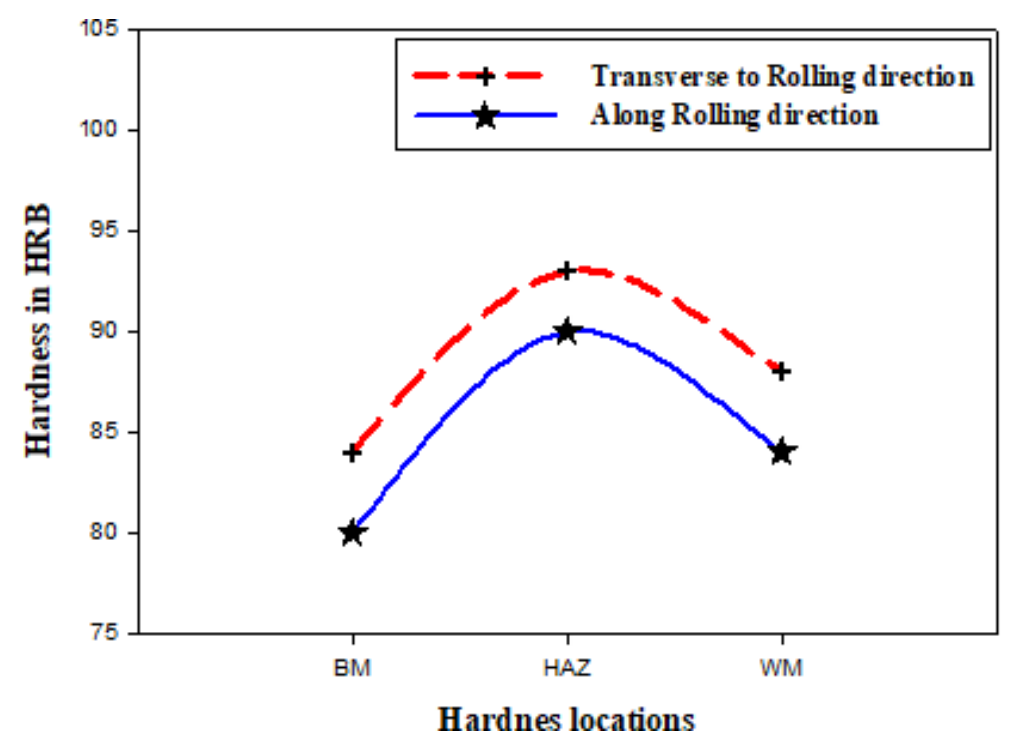

Figure 7. Section hardness across the weld run.

\subsection{DEFLECTION ANALYSIS BY FEA}

\subsubsection{Heat source model and thermal analysis}

Welding process simulation can be employed for thermal and mechanical analyses. In the thermal analysis, the temperature represents a function of time, and in mechanical analysis, the stain as a result of stresses integrated at nodal points. In the SMAW process, the heat source is a consumable electrode. To simulate the welding process in a finite element method, the moving heat source stayed at the element with a constant specific volume heat generation was incorporated at an adequate interval to match with the actual welding speed. Thermal energy is dissipated by conduction, convection, and radiation in the solid. Conduction in the solid is predominating among the heat transfers. The heat generated from the consumable is handled for melting and transferring to the base metal in the form of weld deposits. Heat generation from the filler metal was the function of electrical parameters and the efficiency of the process. Welding arc current remains the variable parameter based on electrode diameter. The FE analysis is based on heat input like welding arc current, arc voltage, and welding speed. Rate of heat input governing equation comprise the following

$q=\left\{\frac{(V I)}{1000 * S}\right\} \eta$

Where $q=$ heat input $(\mathrm{kJ} / \mathrm{mm}), V=\operatorname{arc}$ voltage $(\mathrm{V}), I=\operatorname{arc}$ current (A), and $S$ $=$ welding speed $\left(\mathrm{mm}-\mathrm{s}^{-1}\right)$. The arc efficiency $(\eta)$ is considered as 0.70 . Heat conduction in rectangle coordinate is given by

$\frac{\partial^{2} \mathrm{~T}}{\partial \mathrm{x}^{2}}+\frac{\partial^{2} \mathrm{~T}}{\partial \mathrm{y}^{2}}+\frac{\partial^{2} \mathrm{~T}}{\partial z^{2}}=\frac{1}{\alpha} \frac{\delta \mathrm{T}}{\delta \mathrm{t}}$

Where $\alpha$ is thermal diffusivity of the material and measure of transient thermal properties with a change in temperature. In the welding process, the governing equation was considered as volumetric heat generation for the three-dimensional transient temperature is given by

$$
\frac{\partial}{\partial x}\left\{k_{x} \frac{\delta T}{\delta x}\right\}+\frac{\delta}{\delta y}\left\{k_{y} \frac{\delta T}{\delta y}\right\}+\frac{\partial}{\partial z}\left\{k_{z} \frac{\partial T}{\partial z}\right\}+Q=\rho(T) C_{p}(T) \frac{\partial T}{\partial t}+v \rho(T) C_{p}(T) \frac{\delta T}{\delta x}
$$


Where $\mathrm{k}$ is thermal conductivity $\left(\mathrm{W} / \mathrm{mm}^{\circ} \mathrm{C}\right)$ of material, and $\mathrm{Q}$ is a volumetric heat source $\left(\mathrm{W} / \mathrm{m}^{3}\right)$. Temperature is the function of spatial coordinates and time, which can be expressed as $\mathrm{T}(\mathrm{x}, \mathrm{y}, \mathrm{z}, \mathrm{t})$. The heat source is expressed as heat generation per unit volume $\left(\mathrm{J} / \mathrm{mm}^{3}\right)$. In this model, the heat was transferred from the center of the weld line to the surrounding elements and the heat conduction was acquired by solving the non-linear heat transfer Gaussian distribution characterized by an averaged radius in which the heat volume $\frac{q_{\max }}{\text {. }}$.

$$
q(x, y)=\frac{q_{\max }}{2 \pi\left(r_{0}\right)^{2}} \exp \left(-\left(x^{2}+y^{2}\right) / 2 r_{0}^{2}\right)
$$

The Gaussian heat source model is represented in Fig. 8. The shape parameters $a, b$ and $c$ of the heat source model selected during the calculation are shown in Table 3. In addition, the heat convection and radiation effect were also considered in this thermal analysis as the secondary and tertiary input heat sources.The material properties were used in this work followed anonlinear relationship as a function of temperature and thermal properties of the base metal, HAZ and the weld metal were assumed as same meant for low carbon steel and presented in Table 4.

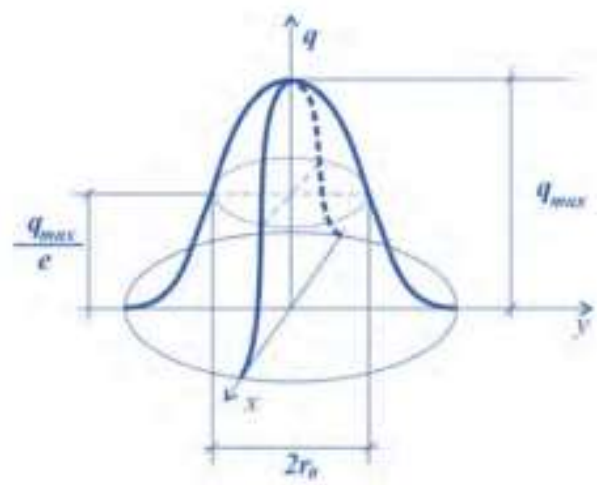

Figure 8. Two-dimensional Gaussian heat source model [13].

The boundary of the welded zone was subjected to convection and radiation, and these effects are also considered in this thermal analysis.

Table 3. Parameters of the heat source

\begin{tabular}{|c|c|c|c|}
\hline Parameters & a & b & c \\
\hline Values in meter & 0.0022 & 0.0018 & 0.0031 \\
\hline
\end{tabular}

The convective heat loss occurring at the surface is represented by equation 5 .

$Q c=-h_{c}\left(T_{s}-T_{0}\right)$

The radiation heat loss was calculated by the Stefan-Boltzmann law, as shown in Eq. 6.

$$
Q_{r}=-\varepsilon \sigma\left(T s^{4}-T o^{4}\right)
$$

Where $\mathrm{Qr}$ is convective heat transfer coefficient. $\varepsilon$ is the emissivity of the surface (considered as 0.7), Ts is surface temperature, and $\mathrm{T}_{0}$ is ambient temperature. The temperature field during welding is shown in Fig.9 and it illustrate the heat source pass through at $\mathrm{t}=35$ seconds after the start of the 
welding. High-temperature gradients are present in the vicinity of the weld line near the top surfaces. The temperature at the rear of the heat source during the welding process shows the cooling phase. It can be observed that the heating rate is very steep, resulting in an almost immediate local heating $\left(9046^{\circ} \mathrm{C}\right)$, followed by a swift cooling time $\left(25^{\circ} \mathrm{C}\right)$.

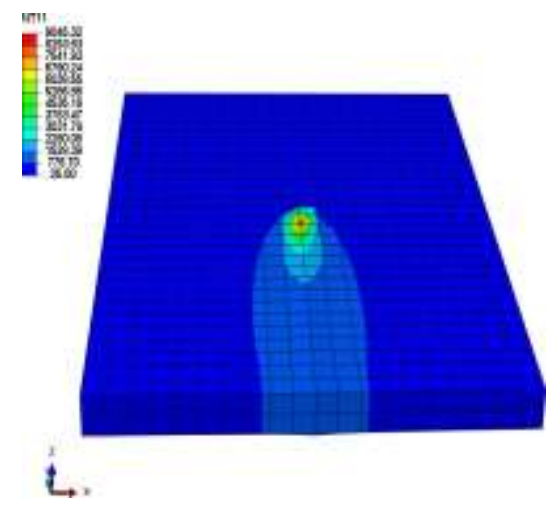

Figure 9. Nodal temperature $\left({ }^{\circ} \mathrm{C}\right)$ at 35 seconds.

\subsubsection{Mechanical analysis}

The strain and welding deformation were based on the simulation results of the temperature field. The element type was changed to a structural element from heat transfer element. Mechanical analysis was evaluated by the application of nodal temperature obtained from the thermal analysis. Newton's second law [15] described the governing equation for mechanical analysis.

$\varepsilon^{e}+\varepsilon^{i}+\varepsilon^{t}=\varepsilon^{T}$

Where $\varepsilon^{\mathrm{T}}$ was total strain, $\boldsymbol{\varepsilon}^{\mathbf{e}}$ was the elastic strain, $\boldsymbol{\varepsilon}^{\mathbf{i}}$ was the inelastic strain, which was calculated from the temperature-dependent stress deviation, the strain hardening, and the plastic yielding. The $\boldsymbol{\varepsilon}^{\mathbf{t}}$ term was the thermal expansion strain, which calculated by $\boldsymbol{\varepsilon}^{\mathbf{t}}=\alpha \Delta \mathrm{T}$, where the $\alpha$ indicated the temperature-dependent coefficient of thermal expansion [16]. The strains induced in the work piece during welding process are presented in Fig.10.(a). and 10 (b) using finite element analysis. Based on the analysis the strain developed due to application of the mechanical load, thermal load, etc. In present case it was thermal loading due to application of welding. It was seen at the start of the welding (run-in) the strains were non-uniform and the specimen was distorted more at the side of the heat source entry. At completion of the welding process and especially after cooling, the strains become more uniform at mid sections of the plate in $\mathrm{X}$ axis. It was observed that the induced strain at mid section was 0.132 when the weld metal deposited along plate rolling (Refer Fig.10. (a)). Whereas the induced strain was 0.104 , when weld metal was deposited transverse to rolling direction (Refer Fig.10.(b)). Conversely, higher strain was observed in transverse to rolling direction and lower strain was in along rolling direction. The induced strain was maximum 0.132 at the mid section of the plate when the weld was laid along the rolling direction i.e. transverse to rolling direction. The yield stress was low because of coarse grains of ferrite and pearlite transverse to rolling that attributed maximum strain. In comparison with the strain induced in 
transverse to plate rolling was higher 13.2\% (Refer Fig.10.(a)) and along the rolling was $10.4 \%$ (Refer Fig 10.(b)).

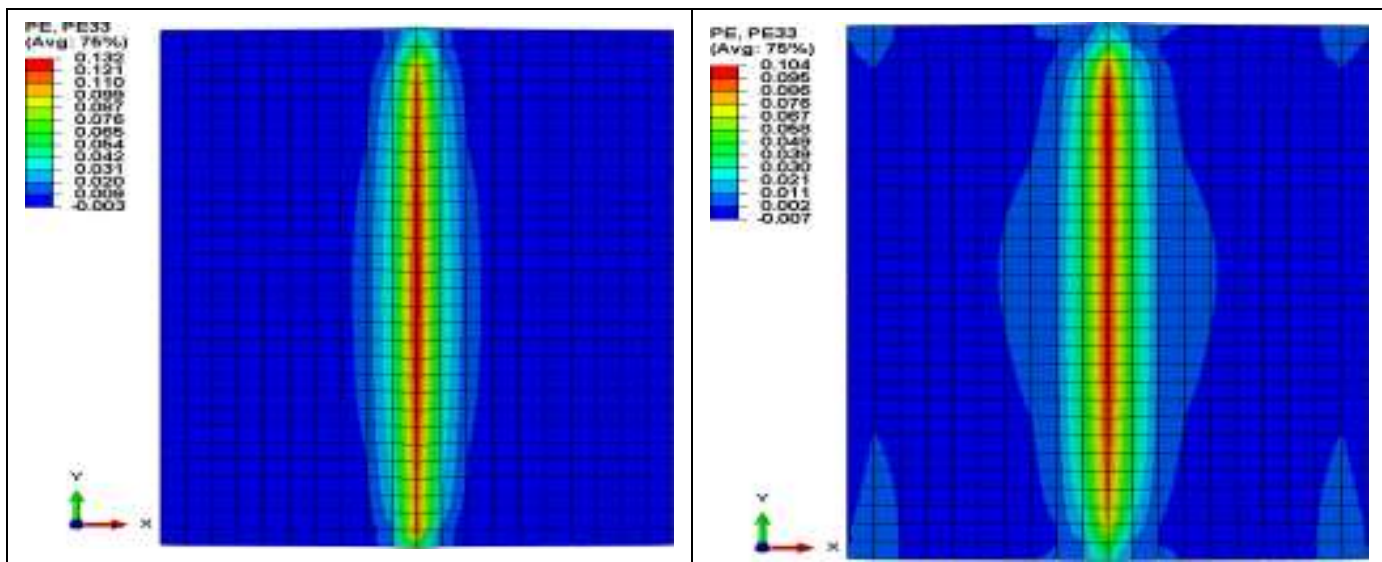

Figure 10. Strain, weld run (a) along plate rolling; (b) transverse to plate rolling 3.3.3. Deflection analysis by FEA and Experiment

The contours of welding induced deflection were computed by FEA for a bead on a plate along with the rolling and transverse to the rolling direction. The profiles of deflection are presented in Fig.11 (a) \& (b). It was identified at the start of the welding (run-in) the deflection were non-uniform, and the specimen was distorted more at the side of the heat source entry. At completion of the welding process and especially after cooling, the deflection becomes uniform at midsections of the plate. The angular distortion of the plate due to contained welding heat input causes differential shrinkages. However, the extent of distortion was based on microstructure changes and physical properties of the material in rolling directions. From Fig.10 (a) \& (b), the maximum angular deflection was about $0.7,0.42 \mathrm{~mm}$ observed in the Z-axis transverse to weld run direction after welding, respectively. The experimental and FEA values of deflections were compared and shown in Fig.11 (a) \& (b). The estimated corresponding angular deflection is given in Table 5. From the Fig.12 (a) \& (b), the deflection was $0.73,0.7 \mathrm{~mm}$ at the weld center when the weld run was laid along the plate rolling direction, whereas the deflection was 0.44 , $0.42 \mathrm{~mm}$ transverse to the rolling direction, respectively.

Table 4. Temperature dependent material properties [14]

\begin{tabular}{|c|c|c|c|c|c|c|c|c|c|c|}
\hline $\begin{array}{l}\text { Temperature } \\
\left({ }^{\circ} \mathrm{C}\right)\end{array}$ & 0 & 100 & 200 & 400 & 600 & 800 & 1000 & 1200 & 1400 & 1550 \\
\hline $\begin{array}{l}\text { Specific heat } \\
\left(\mathrm{J}^{\circ} \mathrm{kg}^{\circ} \mathrm{C}\right)\end{array}$ & 480 & 500 & 520 & 650 & 750 & 1000 & 1200 & 1400 & 1600 & 1700 \\
\hline $\begin{array}{l}\text { Conductivity } \\
\left(\mathrm{W} / \mathbf{m}^{\circ} \mathrm{C}\right)\end{array}$ & 60 & 50 & 45 & 38 & 30 & 25 & 26 & 28 & 37 & 37 \\
\hline $\begin{array}{l}\text { Density } \\
\left(\mathrm{kg} / \mathrm{m}^{3}\right)\end{array}$ & 7880 & 7800 & 7800 & 7760 & 7600 & 7520 & 7390 & 7300 & 7250 & 7180 \\
\hline $\begin{array}{l}\text { Thermal } \\
\text { expansion } \\
\left(10^{-5} /{ }^{\circ} \mathrm{C}\right)\end{array}$ & 1.15 & 1.2 & 1.3 & 1.42 & 1.45 & 1.45 & 1.45 & 1.45 & 1.45 & 1.45 \\
\hline $\begin{array}{l}\text { Young's } \\
\text { modulus } \\
(\text { GPa) }\end{array}$ & 210 & 200 & 200 & 170 & 80 & 35 & 20 & 15 & 10 & 10 \\
\hline Poisson ratio & \multicolumn{10}{|c|}{0} \\
\hline
\end{tabular}



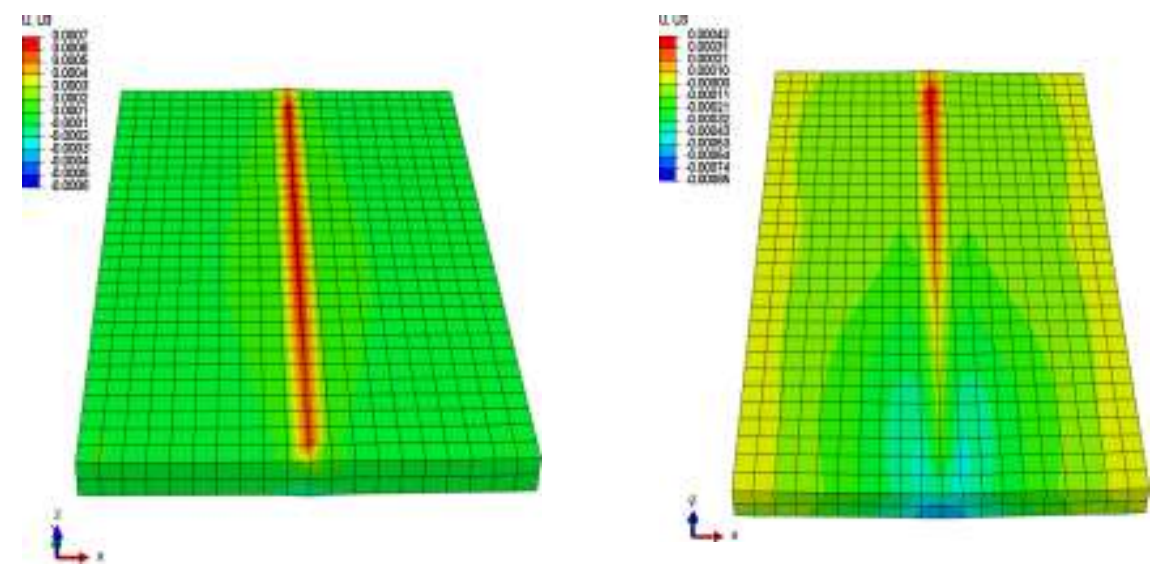

Figure 11. Deflection, weld run (a) along plate rolling; (b) transverse to plate rolling
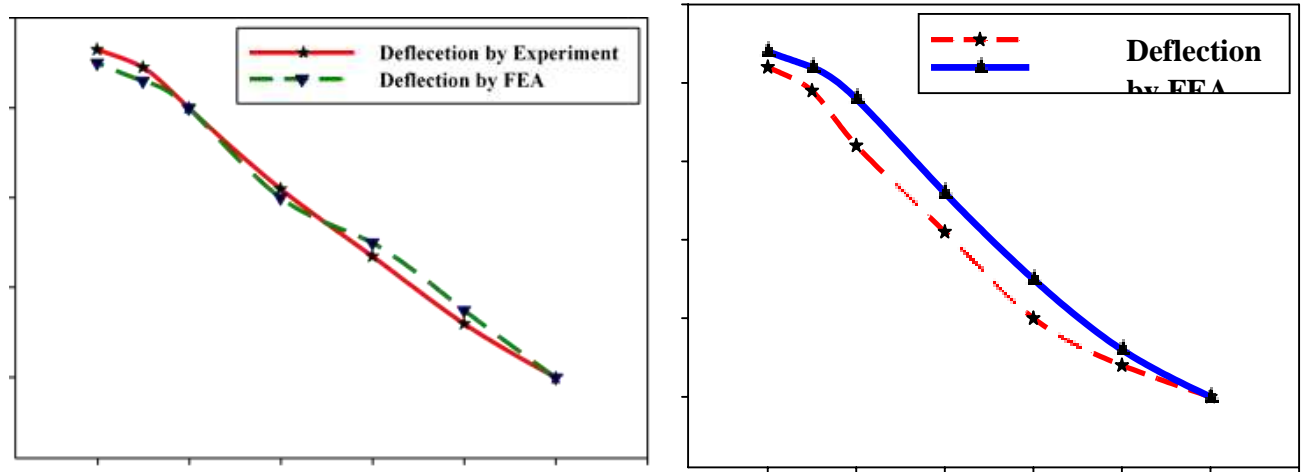

Fig.12. Deflection, weld run (a) along the rolling direction; (b) transverse to the rolling direction

The deflection was intense at the center of the plate due to weld shrinkage. The variation in angular deflection with respect to rolling direction was due to anisotropy properties of the plate rolling directions. The microstructure orientation and dislocation of the grains remain critical parameters for variations in the mechanical properties of as-rolled plates. Welding induced deformation was based on procedures, welding parameters, and material properties. The higher yield strength along the rolling direction resulted in less distortion.

Table 5. The estimated angular deflection

\begin{tabular}{|c|c|c|c|c|c|}
\hline \multirow[t]{2}{*}{ Description } & \multicolumn{2}{|c|}{ Experimental } & \multicolumn{2}{|c|}{$\begin{array}{l}\text { Finite element } \\
\text { analysis }\end{array}$} & \multirow[t]{2}{*}{$\begin{array}{c}\% \\
\text { Error }\end{array}$} \\
\hline & $\begin{array}{l}\text { Deflection } \\
\text { in } \mathrm{mm}\end{array}$ & $\begin{array}{l}\text { Angle in } \\
\text { degree }(\beta)\end{array}$ & $\begin{array}{l}\text { Deflection } \\
\text { in } \mathrm{mm}\end{array}$ & $\begin{array}{l}\text { Angle in } \\
\text { degree }(\beta)\end{array}$ & \\
\hline Along Rolling & 0.73 & $\beta=0.836^{\circ}$ & 0.7 & $\begin{array}{c}\beta= \\
0.802^{\circ}\end{array}$ & 4.3 \\
\hline Transverse to rolling & 0.44 & $\beta=0.504^{\circ}$ & 0.42 & $\begin{array}{c}\beta= \\
0.481^{\circ}\end{array}$ & 4.7 \\
\hline
\end{tabular}




\section{CONCLUSIONS}

Experiments were carried out and analyzed to assess the influence of anisotropy properties of the as-rolled C-Mn plate on welding induced deflection for both the rolling direction of the plate.

The following conclusions were arrived based on test results:

* The base metal contains fine grains ferrite and pearlite with along rolling and coarse grains of ferrite and pearlite transverse to the rolling direction. The coarse-grained ferrite and pearlite were responsible for formation of hard structure like tempered bainite in HAZ after welding. High hardness 94 HRB in HAZ that leading to higher distortion on transverse to the rolling direction. Whereas less deflection along the rolling direction in which fine grains of ferrite and pearlite in base metal. The fine grains of ferrite and pearlite attributed to low hardness in HAZ.

* In any welding process, the extent of deflection was a function of yield strength present in the base metal. Less deflection when the yield strength was $322 \mathrm{MPa}$ along the rolling and higher deflection when the yield strength was 319 MPa in transverse to rolling.

* The severer thermal strain was observed in transverse to rolling direction when the weld metal was deposited along the rolling direction. Whereas moderately lower strain along the rolling of the plate when the weld metal was deposited transverse to rolling. It was revealed that the severer thermal strain attributed due to low yield strength and coarse grains of ferrite and pearlite.

* Welding induced angular deflection drawn from the experiment for weld run along rolling direction was $0.73 \mathrm{~mm}$, and transverse to rolling direction was $0.44 \mathrm{~mm}$. From FEA, the angular deflection weld run along the rolling direction was $0.7 \mathrm{~mm}$, and transverse to rolling direction was $0.42 \mathrm{~mm}$. Angular deflections were compared with experiment and FEA and found that the error was within 5\%.

* Based on Experiments and FEA, the test results were concluded that the angular deflection was high when the yield strength was low and validated the influence of Anisotropy properties had affected on the angular deflection. The test results from experiment and FEA were indicating good agreement.

* The anisotropy properties were established on plate rolling direction. The outcome could enhance the minimum distortion on cutting of the plate, which could reduce the distortion and improve the Product Quality during fabrication process.

\section{ACKNOWLEDGMENT}

The authors would like to thank "National Institute of Technology," for testing in their laboratory and M/s Dee Dee Engineering Enterprises, Tiruchirappalli, India, to carry out experiments at their works.

\section{REFERENCES}

[1] Soul.F, Hamdy.N., Numerical Simulation of Residual Stress and Strain Behaviour After Temperature Modification (2012).

[2] Ray. S., Principles and Applications of Metal Rolling, Cambridge University Press, Delhi, India, (2015).

[3] Panigrahi. B. K., Processing of low carbon steel plate and hot strip-an overview, Bull. Mater. Sci., Vol. 24, No. 4, August (2001), pp. 361-371. 
[4] Donald R. A., Pradeep P. F., Wendelin J.W., The Science and Engineering of Materials, Sixth edition, Australia-Brazil-Japan-Korea-Mexico-SingaporeSpain-United Kingdom-United States, (2010).

[5] Verhaeghe.G, Predictive Formula for weld distortion -A Critical review, Abingto Publishing, (2000).

[6] Radaj.D, Welding residual stress and distortion calculation and measurement, Wood head Publishing Ltd., DVS Verlag, (2003).

[7] Deng.D, Murakawa. H, Ueda.Y, International Journal of Offshore and Polar engineering. 14(2) 2004, pp. 138-144.

[8] Zhu, M. H., Zhao, Y. G., Cai, W., Wu, X. S., Gao, S. N., Wang, K., Luo, L. B.,Huang, H.S. and Lu, L., Spin-glass shell and magneto transport properties of a La0.67 Ca 0.33MnO3 nanoring network, Physical review B, 75, 2007

[9] Cheng. C.M, Chou, C.P, Lee. I.K, Lin. H.Y Distortion Analysis of Single V-groove Butt Welding on Heat Treatable Aluminum Alloys, 21(5), (2005) pp.738-742.

[10] Hensel, A. and Lehnert, L., neue hutte, 18: 654, (1973).

[11] Adil.G.K, Bhole.S.D. HAZ hardness and microstructure predictions of arc welded steel-I review predictive models. Can Mwtall Quart 1992:31(2):pp.151157.

[12] Ramasamy.N, Jeyasimman.D, Kathiravan.R, Raju.N, Influence of welding sequence on residual stresses induced in As-welded Plug weld of low Carbon steel plate, An International Journal of Minerals, Metals and Materials Engineering, Vol.72, Issue:5, (2019), pp.1361-1369.

[13] Jerzy Winczek. The influence of the heat source model selection on mapping of heat affected zones during surfacing by welding, Journal of Applied Mathematics and Computational Mechanics 15 (2016), 167-178.

[14] Dragi Stamenković and Ivana Vasović, Finite element analysis of residual stress in butt welding two similar plates, Scientific Technical Review 9 (2009), pp 57-60.

[15] Yi.Z, Jing, Finite element simulation and experimental validation of distortion and cracking failure phenomena in direct metal laser sintering fabricated component, Addit.Manuf. 16 (2017) 49-57.

[16] Hailaing Хиа, Xingye Guoa, Yongping Leia, Jian Lina, Hanguang Fua, Rongshi Xiaob,Ting Huangb, Yung C. Shinc, Welding deformation of ultra-thin 316 stainless steel plate using pulsed laser welding process, Optics and Laser Technology 119 (2019). 105583. 